\title{
Effectiveness of therapeutic physical exercise in the treatment of patellofemoral pain syndrome: a systematic review
}

\author{
Pablo Alba-Martín ${ }^{1)}$, T Gallego-Izquierdo ${ }^{1)}$, Gustavo Plaza-Manzano ${ }^{2)}$, \\ Natalia Romero-Franco ${ }^{3}$, Susana Núñez-Nagy ${ }^{1)}$, Daniel Pecos-Martín ${ }^{1)^{*}}$ \\ 1) Physiotherapy and Nursery Department, University of Alcalá: E-28871, Madrid, Spain \\ 2) Rehabilitation and Physical Medicine Department, Medical Hydrology, Complutense University, \\ Spain \\ 3) Physiotherapy Department, Catholic University of San Antonio, Spain
}

\begin{abstract}
Purpose] The aim of this study was to analyze the effectiveness of conservative treatment of patellofemoral pain syndrome with physical exercise. [Subjects and Methods] A computer-based review conducted of four databases (PubMed, the Cochrane Library, PEDro, and the University Library) was completed based on the inclusion criteria of patellofemoral pain syndrome patients treated with physical exercise methods and examination with self-reported pain and/or functional questionnaires. [Results] The findings of ten clinical trials of moderate to high quality were evaluated to determine the effectiveness of physical exercise as conservative management for patellofemoral pain syndrome. [Conclusion] The intervention programs that were most effective in relieving pain and improving function in patellofemoral pain syndrome included proprioceptive neuromuscular facilitation stretching and strengthening exercises for the hip external rotator and abductor muscles and knee extensor muscles. Key words: Patellofemoral pain syndrome, Physical exercise
\end{abstract}

(This article was submitted Feb. 23, 2015, and was accepted Mar. 24, 2015)

\section{INTRODUCTION}

Patellofemoral pain syndrome (PFPS) is a structural disorder of the patellofemoral joint whose main characteristics are peripatellar, anterior, and even retropatellar pain that increases with knee flexion and extension (i.e., actions such as running, going up and down stairs, walking, and squatting and postures such as prolonged sitting or sitting on the knees $)^{1,2)}$. Joint crepitus in flexion movements and instability in loading actions are also frequent ${ }^{2}$.

The factors that contribute to PFPS are unclear. Many authors have suggested risk factors, including weak extensor musculature primarily in the vastus medialis ${ }^{3)}$, a high body mass index ${ }^{4}$, misalignment of the lower limbs, and excessive foot pronation that internally rotates the tibia and increases knee valgus ${ }^{2}$; however, some scientific evidence suggests that these are not risk factors ${ }^{2-4)}$.

Because PFPS is a non-degenerative pathology, conservative management often results in complete recovery, particularly in young patients ${ }^{2)}$. However, the appropriate clinical approach to this syndrome remains unclear due to the

*Corresponding author. Daniel Pecos-Martín (E-mail: daniel. pecos@uah.es)

C2015 The Society of Physical Therapy Science. Published by IPEC Inc. This is an open-access article distributed under the terms of the Creative Commons Attribution Non-Commercial No Derivatives (by-ncnd) License $<$ http://creativecommons.org/licenses/by-nc-nd/3.0/> . variety of treatments that have been applied and the studies that have analyzed the pathology of PFPS. Although some reviews addressing PFPS have been conducted, no author has yet reviewed all physical exercise methods for patients with PFPS ${ }^{5-8)}$. Thus, this study aims to perform a systematic review to determine whether conservative treatments that employ physical exercise improve the pain and function of patients with patellofemoral pain syndrome.

\section{SUBJECTS AND METHODS}

Clinical trials related to PFPS were considered if they included physical exercise as a conservative management and included instruments that measured pain, such as pain scales, and function. No year limitations were included to avoid the exclusion of relevant results, and English, Spanish, French, and Portuguese were the languages considered. Studies were excluded if the analyzed population included individuals suffering from associated diseases or included surgery or management approaches involving nonphysical methods.

In the computer-based search, PubMed, Cochrane Library, Physiotherapy Evidence Database (PEDro), and the University Library of the city database were considered. The following keywords were used: "patellofemoral pain syndrome" $[\mathrm{MeSH}]$, "physical therapeutic modalities" [MeSH], "physical therapy" [MeSH], and "physical exercise" [MeSH].

The Critical Appraisal Skills Program in Spanish 
Table 1. Methodological quality of studies using the CASPe scale (Critical Appraisal Skills Program in Spanish)

\begin{tabular}{lccccccccccc}
\hline \multirow{2}{*}{ Author } & \multicolumn{110}{c}{ CASPe items } \\
\cline { 2 - 11 } & 1 & 2 & 3 & 4 & 5 & 6 & 7 & 8 & 9 & 10 & 11 \\
\hline Herrington et al. & $\checkmark$ & $\checkmark$ & $\checkmark$ & $x$ & $\checkmark$ & $\checkmark$ & $\checkmark$ & $\checkmark$ & $\checkmark$ & $\checkmark$ & $\checkmark$ \\
Syme G et al. & $\checkmark$ & $\checkmark$ & $x$ & $x$ & $\checkmark$ & $\checkmark$ & $\checkmark$ & $\checkmark$ & $\checkmark$ & n/a & $x$ \\
Dolak KL et al. & $\checkmark$ & $\checkmark$ & $x$ & $x$ & $\checkmark$ & $\checkmark$ & $\checkmark$ & $\checkmark$ & $\checkmark$ & $\checkmark$ & $\checkmark$ \\
Fukuda TY et al. & $\checkmark$ & $\checkmark$ & $x$ & $x$ & $\checkmark$ & $\checkmark$ & $\checkmark$ & $\checkmark$ & $\checkmark$ & $\checkmark$ & $\checkmark$ \\
Avraham F et al. & $\checkmark$ & $\checkmark$ & $x$ & $x$ & $\checkmark$ & $\checkmark$ & $x$ & $\checkmark$ & $\checkmark$ & n/a & $\checkmark$ \\
Khamyambashi K et al. & $\checkmark$ & $\checkmark$ & $\checkmark$ & $x$ & $\checkmark$ & $x$ & $\checkmark$ & $\checkmark$ & $\checkmark$ & $\checkmark$ & $\checkmark$ \\
Khamyambashi K et al. & $\checkmark$ & $\checkmark$ & $\checkmark$ & $x$ & $\checkmark$ & $\checkmark$ & $x$ & $\checkmark$ & $\checkmark$ & $\checkmark$ & $\checkmark$ \\
Nakagawa TH et al. & $\checkmark$ & $\checkmark$ & $\checkmark$ & $x$ & $\checkmark$ & $\checkmark$ & $x$ & $\checkmark$ & $\checkmark$ & $x$ & $\checkmark$ \\
Moyano FR et al. & $\checkmark$ & $\checkmark$ & $\checkmark$ & $x$ & $\checkmark$ & $\checkmark$ & $\checkmark$ & $\checkmark$ & $\checkmark$ & $\checkmark$ & $\checkmark$ \\
Lee J et al. & $\checkmark$ & $\checkmark$ & $\checkmark$ & $x$ & $\checkmark$ & $\checkmark$ & $x$ & $\checkmark$ & $x$ & $\checkmark$ & $x$ \\
\hline
\end{tabular}

$\checkmark=$ Yes; $\mathbf{x}=$ No; $/ \mathrm{a}=$ not applicable

CASPe items: 1. The clinical trial was focus on a clearly defined question. 2. Groups were randomly assigned. 3. All patients were considered until the end of the study. 4. Triple blind study; 5. Groups were similar at the beginning of study. 6 . Regardless of the intervention, groups were equally considered. 7. Effect size of treatment. 8. Accuracy of treatment's estimated effect. 9. Results applicable to the local population. 10. All results were considered clinically relevant. 11. Risks and costs were justified.

$(\mathrm{CASPe})^{9)}$ was the scale employed to measure the methodological qualities and validities of the selected articles (Table 1). Three investigators independently evaluated every article.

\section{RESULTS}

The search strategy initially produced 90 articles. After analysis, ten studies were considered to have met the inclusion criteria. Table 1 shows the quality evaluations of the selected articles with the CASPe scale. There was agreement in the scoring of all studies between the three investigators who evaluated the studies according the CASPe scale. The highest CASPe score was 10/10, and the average was 8.5.

The ten studies involved 420 subjects, with age most frequently ranging between 18-35 years (Table 2).

The pain assessment tools included the VAS (Visual Analogical Scale) in the majority of studies, the NPRS (Numeric Pain Rating Scale), AKPS (Anterior Knee Pain Scale), and MPQ (McGill Pain Questionnaire) were also employed (Table 2). The function assessment tools included a high variety of scales that involved general health status (HS, Health Status; WOMAC, Western Ontario and McMaster Universities Osteoarthritis Index; FIQ, Functional Index Questionnaire; SF36, Short form-36 Health Survey) and local knee function (KES, Knee Extension Strength; LEFS, Lower Extremity Function Scale; ISM, Isometric Strength Measurement; PFJES, Patello-femoral Joint Evaluation Scale).

Regarding the intervention, two studies employed exercises for the knee extensor muscles; seven studies included exercises for the external rotators and hip abductor muscles; and one study considered stretching exercises in addition to physical exercise (Table 2). Studies of interventions that included knee extensor exercises reported reduced pain and improved knee function due to an increase in the extension force and range of motion of the knee in PFPS patients. Studies that included exercises for the hip external rotators and abductor muscles reported that the combination of hip external rotator, abductor, and quad strengthening reported lower values for pain level and function earlier than quad strengthening alone. The study that included stretching exercises revealed improvements in pain, function, and the range of motion of the knee, but these results were observed when the stretching protocol included PNF (proprioceptive neuromuscular facilitation) techniques (Table 2).

\section{DISCUSSION}

The main finding of the present systematic review is that physical therapy protocols based on strengthening exercises of the hip external rotators and the abductor muscles results in greater pain relief among PFPS patients than those based only on strengthening exercises for the quadriceps ${ }^{10,11)}$. Stretching exercises for the muscles of the knee and hip also improved the function, pain and range of motion of PFPS patients, and PNF was the most appropriate type of stretching exercise to add to active exercise.

Previously, quadriceps strengthening has been reported to exert pain, and function benefits in PFPS $2,10,20,21)$ because patellar misalignment may be induced by a greater force from the vastus medialis ${ }^{22,23)}$. However, a study by Syme et al. ${ }^{11)}$ showed that specific exercises for the vastus medialis resulted in the same level of pain relief as general exercises for the quadriceps muscle ${ }^{11)}$. Supporting these results, Cowan et al. ${ }^{24)}$ reported a nonsignificant difference between activations of the vastus medialis and vastus lateralis, which is suggestive of the difficulty of selectively activating the vastus medialis muscle ${ }^{24)}$.

Also, authors have stated that the isolated performance of quadriceps exercises during the initial phase of PFPS 
Table 2. Main aspects of the studies included

\begin{tabular}{|c|c|c|c|}
\hline $\begin{array}{l}\text { Authors } \\
\text { (sample size: gender; age) }\end{array}$ & Characteristics of sample & Jariables & Results \\
\hline $\begin{array}{l}\text { Herrington et al. } \\
(\mathrm{n}=45 \text { : male; } 18-35 \text { years })\end{array}$ & $\begin{array}{l}6 \text { wk: SJNWBE }(n=15) \text { vs MJWBE } \\
(n=15) \text { vs any exercise }(n=15)\end{array}$ & S, MKS & $\begin{array}{l}\text { All patients improved knee pain, } \\
\text { function, extension strength. }\end{array}$ \\
\hline $\begin{array}{l}\text { Syme et al. } \\
(\mathrm{n}=69 \text { : gender and age not } \\
\text { specified) }\end{array}$ & $\begin{array}{l}8 \text { wk: vastus medialis selective exer- } \\
\text { cises }(n=23) \text { vs quad general exercises } \\
(n=23) \text { vs any exercise }(n=23)\end{array}$ & $\begin{array}{l}\text { MPQ, MFIQ, SF-36, } \\
\text { PGI }\end{array}$ & $\begin{array}{l}\text { Both intervention groups similarly } \\
\text { reduced pain and improved knee function. }\end{array}$ \\
\hline $\begin{array}{l}\text { Dolak et al. } \\
\text { ( } \mathrm{n}=26 \text { : female; } 16-35 \text { years) }\end{array}$ & $\begin{array}{l}4 \text { wk: hip external rotators and abduc- } \\
\text { tors muscle exercises }(n=17) \text { vs quad } \\
\text { exercises }(n=16)\end{array}$ & $\begin{array}{l}\text { AS, LEFS, HABD, } \\
\text { ER, KES }\end{array}$ & $\begin{array}{l}\text { Hip exercises resulted in pain relief and } \\
\text { higher hip muscles strength after the } \\
\text { first } 4 \text { weeks. At } 8 \text { weeks, both groups } \\
\text { showedimprovemalet. }\end{array}$ \\
\hline $\begin{array}{l}\text { Fukuda et al. } \\
(\mathrm{n}=64 \text { : gender not specified; } \\
18-32 \text { years) }\end{array}$ & $\begin{array}{l}4 \text { wk: knee muscles exercises }(n=20) \text { vs } \\
\text { knee muscle }+ \text { hip muscles exercises } \\
(n=21) \text { vs any exercise }(n=23)\end{array}$ & $\begin{array}{l}\text { NPRS, LEFS, } \\
\text { AKPS, SLSHT }\end{array}$ & $\begin{array}{l}\text { Both intervention groups showed similar } \\
\text { improvemalets in pain and function. }\end{array}$ \\
\hline $\begin{array}{l}\text { Avraham et al. } \\
(\mathrm{n}=30 \text { : gender not specified; } \\
35 \text { years average) }\end{array}$ & $\begin{array}{l}3 \text { wk: quad exercises }+ \text { TENS }(n=10) \\
\text { vs hip external rotators and abductors } \\
\text { exercises }+ \text { TENS }(n=10) \text { vs knee and } \\
\text { hip exercises }+ \text { TENS }(n=10)\end{array}$ & & $\begin{array}{l}\text { Both intervention groups had pain and } \\
\text { function improvemalets, but group } 3 \text { had } \\
\text { significantly higher improvemalets. }\end{array}$ \\
\hline $\begin{array}{l}\text { Khamyambasi et al. } \\
(\mathrm{n}=28 \text { : female; } 29 \text { years } \\
\text { average) }\end{array}$ & $\begin{array}{l}8 \text { wk: hip muscles exercises }(n=14) \text { vs } \\
\text { placebo treatmalet }(n=14)\end{array}$ & $\begin{array}{l}\text { WOMAC, } \\
\text { it wk and } 6 \\
\text { hs }\end{array}$ & $\begin{array}{l}\text { Hip exercises resulted in less pain and } \\
\text { higher health status in short and long } \\
\text { terms. }\end{array}$ \\
\hline $\begin{array}{l}\text { Khamyambasi et al. } \\
(\mathrm{n}=36 \text { : male and female; } \\
28 \text { years average) }\end{array}$ & $\begin{array}{l}\text { lateral exercises } \\
\text { eps exercises }(n=18)\end{array}$ & $\begin{array}{l}\text { VAS, WOMAC; at } 8 \\
\text { wk and } 6 \text { months }\end{array}$ & $\begin{array}{l}\text { Hip exercises resulted in less pain and } \\
\text { higher health status in short and long } \\
\text { terms. }\end{array}$ \\
\hline $\begin{array}{l}\text { Nakagawa et al. } \\
(n=14: \text { male and female; } \\
17-40 \text { years })\end{array}$ & $\begin{array}{l}6 \text { wk: quadriceps exercises and hip ex- } \\
\text { ternal rotators and abductors exercises } \\
(n=14) \text { vs quadriceps exercises }(n=14)\end{array}$ & $\begin{array}{l}\text { VAS, EIKEPT, } \\
\text { HAHLREPT, EMG } \\
\text { of gluteal medialis }\end{array}$ & $\begin{array}{l}\text { Hip+quad exercises resulted in less pain } \\
\text { and an increase in electromyographic } \\
\text { activity in the gluteal medialis. }\end{array}$ \\
\hline $\begin{array}{l}\text { Moyano et al. } \\
(\mathrm{n}=74 \text { : gender not specified; } \\
40.2 \pm 3.29 \text { years })\end{array}$ & $\begin{array}{l}16 \text { wk: classic stretching }(\mathrm{n}=35) \text { vs } \\
\text { PNF stretching }(\mathrm{n}=33) \text { vs educational } \\
\text { intervention }(\mathrm{n}=26)\end{array}$ & $\begin{array}{l}\text { AKPS, VAS, Q- } \\
\text { angle, thigh perim- } \\
\text { eter, knee ROM }\end{array}$ & $\begin{array}{l}\text { PNF and aerobic exercise improved func- } \\
\text { tion, pain, and ROM after } 16 \text { weeks and } \\
\text { had better results than classic stretching }\end{array}$ \\
\hline $\begin{array}{l}\text { Lee } J \text { et al. } \\
(\mathrm{n}=34: \text { male and female; } \\
22.8 \pm 3.4 \text { years })\end{array}$ & $\begin{array}{l}\text { 8wk: elastic band exercises }(n=11) \text { vs } \\
\text { sling exercises }(n=13) \text { vs control group } \\
(n=10)\end{array}$ & $\begin{array}{l}\text { Dynamic Q-angle, } \\
\text { VAS, onset time VL, } \\
\text { onset time VMO }\end{array}$ & Both intervention groups improved pain \\
\hline
\end{tabular}

VAS: Visual Analogue Scale; SJNWBE: Single joint quadriceps exercise; MJWBE: multiple-joint quadriceps exercise; TENS: Transcutaneous Electrical Nerve Stimulation; KES: Knee Extension Strength; KPS: Kujala Patellofemoral Score; ISM: Isometric Strength Measurement; FIQ: Functional Index Questionnaire; HAHLREPT: Hip Abductor and Hip Lateral Rotators Eccentric Peak Torque; EIKEPT: Eccentric Isokinetic Knee Extensor Peak Torque; WOMAC: Western Ontario and McMaster Universities Osteoarthritis Index; HS: Health Status; PFJES: Patello-femoral Joint Evaluation Scale; NPRS: Numeric Pain Rating Scale; LEFS: Lower Extremity Function Scale; AKPS: Anterior Knee Pain Score; SLSHT: Single-limb Single Hop Test; HABD: hip abductors; HER: hip external rotators; MKS: Modified Kujala Questionnaire; MPQ: McGill Pain Questionnaire; MFIQ: Modified Functional Index Questionnaire; PGI: Patient Generated Index; SF-36: Short form-36 Health Survey; ROM: range of motion; VL: vastus lateralis; VMO: vastus medialis oblique; FPPA: frontal plane proyection angle of the knee; EMG: electromiography

rehabilitation might irritate the patellofemoral structures due to the effects of the high levels of pressure and force during the exercises on weak knee extensor musculature ${ }^{11)}$. Therefore, many authors have recently added exercises for the external rotators and abductor muscles to PFPS treatment protocols ${ }^{12,13,15-18)}$ due to the biomechanical influences of these muscles on femur alignment: a lack of motor control from the hip external rotators and abductor muscles would increase femur rotation under the patella while standing. Additionally, the performance of quadriceps strengthening exercises with a weak extensor musculature increases the pressure and force on the patellofemoral structures ${ }^{25}$. Nakagawa et al. ${ }^{14)}$ and Fukuda et al. ${ }^{13)}$ reported greater pain relief when patients performed a combination of exercises for the hip external rotators, abductor, and quadriceps muscles compared with quadriceps exercises alone ${ }^{13,14)}$. Nakagawa also reported greater electromyographic activation of the gluteus medialis, which is directly related to pain relief and functional improvements ${ }^{14)}$. This finding might explain the pain relief that was experienced by patients while walking down stairs ${ }^{13}$ ) (a situation in which the hip muscles are needed for motor control $\left.{ }^{25}, 26\right)$ in the study by Fukuda et $\mathrm{a}^{13)}$. Similarly, Dolak et al. ${ }^{12)}$ reported earlier pain relief when participants performed 4 weeks of exercises for the external rotators and abductor muscles compared with exercises for the quadriceps muscle; both of these programs were performed prior to 4 weeks of functional rehabilitation ${ }^{12)}$. Moreover, Khayambashi et al. reported that the performance of isolated hip strengthening reduced pain intensity and improved health status compared with a placebo interven- 
tion $^{25)}$. Later, Khayambashi et al. ${ }^{16,}{ }^{17)}$; demonstrated that hip posterolateral exercises produced greater pain relief and a better health status than quadriceps exercises did, and these improvements were maintained after 6 months ${ }^{16,17)}$.

In addition, stretching of knee and hip muscles might help improve pain, function, and range of motion in PFPS patients. However, among the stretching exercises, the PNF type seems to be more effective than classic stretching in terms of pain relief, functional improvements, and knee range of motion ${ }^{19)}$.

Although many authors have examined the influences of the hip external rotator and abductor muscles on PFPS management ${ }^{13-18}$ ), the etiology of this syndrome remains unclear. Future research is needed to identify the etiologic mechanism and create more adequate treatments. Also, the high variety of methods to assess pain used by the authors of the studies included in this review hampers comparison of their results. While the majority of the studies used the Visual Analog Scale as the instrument to determine pain levels, the McGill Pain Questionnaire and Anterior Knee Pain Scale were also frequently employed to assess pain. Regarding function, the variety is higher, which makes the comparison of results very difficult.

The most effective patellofemoral pain syndrome management initially includes strengthening exercises for the hip external rotator and abductor muscles due to their roles in knee biomechanics. The addition of exercises for the extensor muscles and proprioceptive neuromuscular facilitation stretching improves the pain relief in PFPS.

\section{REFERENCES}

1) Paniagua JD, de la Alberca MJL. Bases científicas para el diseño de un programa de ejercicios para el síndrome de dolor femoropatelar. 2010.

2) Heintjes EM: Non-traumatic knee complaints in adolescents and young adults in general practice, Erasmus University Rotterdam; 2006.

3) Haupenthal A, Bento A, Avalos VD, et al.: Tratamiento fisioterapeutico en el síndrome patelofemoral (SPF). Un estudio de caso. Revista Digital Buenos Aires, 2006, 11

4) Callaghan MJ, Selfe J: Patellar taping for patellofemoral pain syndrome in adults. Cochrane Database Syst Rev, 2012, 4: CD006717. [Medline]

5) Peters JS, Tyson NL: Proximal exercises are effective in treating patellofemoral pain syndrome: a systematic review. Int J Sports Phys Ther, 2013 8: 689-700. [Medline]

6) Clijsen R, Fuchs J, Taeymans J: Effectiveness of exercise therapy in treatment of patients with patellofemoral pain syndrome: systematic review and meta-analysis. Phys Ther, 2014, 94: 1697-1708 [Epub ahead of print]. [Medline] [CrossRef]

7) Kooiker L, Van De Port IG, Weir A, et al.: Effects of physical therapistguided quadriceps-strengthening exercises for the treatment of patellofemoral pain syndrome: a systematic review. J Orthop Sports Phys Ther, 2014, 44: 391-B1. [Medline] [CrossRef]

8) Rixe JA, Glick JE, Brady J, et al.: A review of the management of patellofemoral pain syndrome. Phys Sportsmed, 2013, 41: 19-28. [Medline] [CrossRef]

9) Cabello J: Plantilla para ayudarte a entender un Estudio de Diagnóstico.
Guías CASPe de Lectura Crítica de la Literatura Médica. Alicante: CASP, 2005 .

10) Herrington L, Al-Sherhi A: A controlled trial of weight-bearing versus non-weight-bearing exercises for patellofemoral pain. J Orthop Sports Phys Ther, 2007, 37: 155-160. [Medline] [CrossRef]

11) Syme G, Rowe P, Martin D, et al.: Disability in patients with chronic patellofemoral pain syndrome: a randomised controlled trial of VMO selective training versus general quadriceps strengthening. Man Ther, 2009, 14: 252-263. [Medline] [CrossRef]

12) Dolak KL, Silkman C, Medina McKeon J, et al.: Hip strengthening prior to functional exercises reduces pain sooner than quadriceps strengthening in females with patellofemoral pain syndrome: a randomized clinical trial. J Orthop Sports Phys Ther, 2011, 41: 560-570. [Medline] [CrossRef]

13) Fukuda TY, Rossetto FM, Magalhães E, et al.: Short-term effects of hip abductors and lateral rotators strengthening in females with patellofemoral pain syndrome: a randomized controlled clinical trial. J Orthop Sports Phys Ther, 2010, 40: 736-742. [Medline] [CrossRef]

14) Nakagawa TH, Muniz TB, Baldon RM, et al.: The effect of additional strengthening of hip abductor and lateral rotator muscles in patellofemoral pain syndrome: a randomized controlled pilot study. Clin Rehabil, 2008, 22: 1051-1060. [Medline] [CrossRef]

15) Avraham F, Aviv S, Ya'akobi P, et al.: The efficacy of treatment of different intervention programs for patellofemoral pain syndrome - a single blinded randomized clinical trial. Pilot study. ScientificWorldJournal, 2007, 7 : 1256-1262. [Medline] [CrossRef]

16) Khayambashi K, Mohammadkhani Z, Ghaznavi K, et al.: The effects of isolated hip abductor and external rotator muscle strengthening on pain, health status, and hip strength in females with patellofemoral pain: a randomized controlled trial. J Orthop Sports Phys Ther, 2012, 42: 22-29. [Medline] [CrossRef]

17) Khayambashi K, Fallah A, Movahedi A, et al.: Posterolateral hip muscle strengthening versus quadriceps strengthening for patellofemoral pain: a comparative control trial. Arch Phys Med Rehabil, 2014, 95: 900-907 [Epub ahead of print]. [Medline] [CrossRef]

18) Lee J, Lee H, Lee W: Effect of weight-bearing therapeutic exercise on the q-angle and muscle activity onset times of elite athletes with patellofemoral pain syndrome: a randomized controlled trial. J Phys Ther Sci, 2014, 26: 989-992. [Medline] [CrossRef]

19) Moyano FR, Valenza MC, Martin LM, et al.: Effectiveness of different exercises and stretching physiotherapy on pain and movement in patellofemoral pain syndrome: a randomized controlled trial. Clin Rehabil, 2013, 27: 409-417. [Medline] [CrossRef]

20) Stiene HA, Brosky T, Reinking MF, et al.: A comparison of closed kinetic chain and isokinetic joint isolation exercise in patients with patellofemoral dysfunction. J Orthop Sports Phys Ther, 1996, 24: 136-141. [Medline] [CrossRef]

21) Witvrouw E, Lysens R, Bellemans J, et al.: Open versus closed kinetic chain exercises for patellofemoral pain. A prospective, randomized study. Am J Sports Med, 2000, 28: 687-694. [Medline]

22) Boling MC, Bolgla LA, Mattacola CG, et al.: Outcomes of a weightbearing rehabilitation program for patients diagnosed with patellofemoral pain syndrome. Arch Phys Med Rehabil, 2006, 87: 1428-1435. [Medline] [CrossRef]

23) Grabiner MD, Koh TJ, Draganich LF: Neuromechanics of the patellofemoral joint. Med Sci Sports Exerc, 1994, 26: 10-21. [Medline] [CrossRef]

24) Cowan SM, Bennell KL, Hodges PW: Therapeutic patellar taping changes the timing of vasti muscle activation in people with patellofemoral pain syndrome. Clin J Sport Med, 2002, 12: 339-347. [Medline] [CrossRef]

25) Powers CM, Ward SR, Fredericson M, et al.: Patellofemoral kinematics during weight-bearing and non-weight-bearing knee extension in persons with lateral subluxation of the patella: a preliminary study. J Orthop Sports Phys Ther, 2003, 33: 677-685. [Medline] [CrossRef]

26) Mascal CL, Landel R, Powers C: Management of patellofemoral pain targeting hip, pelvis, and trunk muscle function: 2 case reports. J Orthop Sports Phys Ther, 2003, 33: 647-660. [Medline] [CrossRef] 